\title{
Applying organizational routines in understanding organizational change
}

Markus C. Becker, Nathalie Lazaric, Richard R. Nelson and Sidney G. Winter

Organizational routines are considered basic components of organizational behavior and repositories of organizational capabilities (Nelson \& Winter, 1982). They do, therefore, hold one of the keys to understanding organizational change. The article focuses on how the concept of organizational routines can be applied in empirical research to understand organizational change. We identify problems encountered in such research and present proposals for how to deal with them, in order to advance our knowledge of routines and our understanding of organizational change. Developing these themes, we also introduce the articles in the special section 'Towards an Operationalization of the Routines Concept'.

\section{Routines as basic components of organizational behavior and repository of organizational capabilities}

Understanding organizational change is one of the great endeavors of students of organizations. One proposition for how to tackle this challenge is to understand organizational change by analyzing how organizational routines change (Nelson and Winter, 1982). Over several decades, a very considerable body of research has built up around the proposition that routines are the basic components of organizational behavior, and the repository of organizational capabilities (March and Simon, 1958; Cyert and March, 1963, Nelson and Winter, 1982; see Becker, 2004, for a review). From this perspective, organizational routines are a crucial part of any account of how organizations accomplish their tasks in society. They also hold one of the keys to understanding change in the economy, and for understanding how organizational capabilities are accumulated, transferred and applied (Cohen etal., 1996; Winter, 2000). Organizational routines are units of analysis that capture change on a microlevel, and then allow us to 'zoom in' and make change, and its driving forces, more visible to the eye of the researcher.

For an aspect of organizational behavior to emerge and persist as a 'routine', there must be a certain amount of stability to the conditions molding behavior: broad policies set by management, the conditions under which the particular routine in question is 
viewed as consistent with organizational goals and policies, explicit or implicit agreements among the various agents involved to do their parts of the actions needed to sustain the routine, etc. But many organizational routines are periodically, or even almost always, in flux. Indeed, a central proposition of routine theory is that organizations change what they are doing and how they are doing it by changing their routines. The change of routines may come at the instigation of management. Or the changes may come largely from forces and actions of agents internal to the routine. Some routines change faster and more drastically than others. For example, in many industries the capability of firms to compete depends on their ability to keep on introducing new products, or improving their processes of manufacture, or both, and such innovating requires continuing change in a range of the routines used in a firm. On the other hand, even for firms in such industries, many routines may be very stable, for example routines involved in inventory management, or pricing, or recruitment.

\section{Applying organizational routines in analyzing organizational change}

Organizational routines are fundamental to understanding change partly because they provide a basic definition of what change 'really is' at the organizational level. Probably few people think that interesting change is involved when the operating routines of an organization produce performance variations in response to variation in familiar input signals-e.g. a restaurant accommodating the changing flow of specific selections that its customers make from its menus. From this point of view, 'no change' is to be understood as 'behavior continues to be guided by the same stable and familiar routines'. That definition is the backdrop for a definition of innovation, or 'real change' as involving change in routines. Routines are also fundamental to change because in some cases they are designed to produce it-e.g. new product development routines - and because in other cases they encompass and provide analytical access to sources of endogenous change (cf. Nelson and Winter, 1982: 128-134). They also help identify the pathways and mechanisms by which exogenous sources of change have an impact on the organization's behavior. Organizational routines are a unit of analysis that capture a level of granularity significant for organizational change. (An analysis that remains too much on a macro-level will be systematically incapable of capturing many interactions and their effects on actors and the environment.) Considering routines enables the researcher to 'zoom in' on micro-level dynamics and identify driving forces of change on that level. Those driving forces of change can be identified when one analyzes organizational routines, because they are intimately connected with organizational routines. In what follows, we highlight some ways in which organizational routines contribute to understanding organizational change. Where applicable, we also describe the contribution of the articles in this special issue to the point identified. 
Key to recognizing that some important sources of change are intimately connected with organizational routines is to recognize that routines are often effortful accomplishments (Pentland and Rueter, 1994; Feldman, 2000, 2003; Feldman and Pentland, 2003, this issue). Organizational routines are malleable by deliberate managerial influence, but also change endogenously because human actors are involved in carrying out routines, and almost always have the possibility to amend the routine (Feldman, 2000, Feldman and Pentland, 2003). Organizational routines are carried out by human beings who may enable and support a certain degree of stability as long as their interests are preserved, as long as participating in the routine in its present form means high status for oneself, as long as it makes sense according to a rationale the actor believes in, etc. Change of routines is linked, at least in part, to the personal visions of the actors carrying out routines, the instability of individual and organizational goals, and negotiations of individual and collective interests (March, 1994).

The papers in this special issue contribute to shed light on understanding the endogenously induced change of organizational routines. Reynaud illustrates how encountering radically new situations requires employees to exercise effort and creativity, such as by adapting rules to circumstances, and suggests interpreting routines as sense making repetition. Lazaric and Denis cast light on how socio-emotional issues during the repetition of tasks had an impact on the stabilization of new routines in a small agro-food firm. Furthermore, they illustrate how the change of organizational practices is driven by the willingness of employees to improve daily tasks.

Organizational routines are also thought to be the repository of organizational capabilities (March and Simon, 1958; Cyert and March, 1963; Nelson and Winter, 1982). Herein lies a second source of endogenous change that is wrapped up with routines. Research on routines as repository of organizational capabilities (Dosi et al., 2000; Winter 2000, 2003; Zollo and Winter, 2002) has emphasized that routines do not just preserve the past. Being a repository of organizational capabilities, they also pave the way for deliberate learning inside firms, thereby shaping the future development of the firm (Winter, 2000; Zollo and Winter, 2002).

The notion of routines as organizational memory and repository of organizational capabilities also comprises a driver of change. Some of the knowledge that routines store has tacit components. Tacit knowledge, however, is susceptible to influence by its bearer when it is applied and replicated, presenting a source of endogenous variation. Analyzing how tacit knowledge is stored, recalled and enacted in organizational routines can provide insights into the biases and drivers of change generated when routines act as organizational memory and repository of organizational capabilities. In this sense, while routines preserve knowledge (organizational memory), they also represent a source of endogenous change of the organization (Becker and Lazaric, 2003).

Lazaric and Denis illustrate the point. In this issue they describe how the articulation of organizational practices was driven by the desire to improve the firm's reputation towards potential acquirers by a credible claim to providing quality through 
reliable practices. Codification also had the effect, however, of changing the traditional ways of doings things, destabilizing recurrent interaction patterns and sense making, and giving rise to resistance against change (see also Reynaud, this issue).

Organizational routines shape a firm's development by engendering path dependence. Specifying the path along which organizations will develop rigidity does in itself make an important contribution to understanding the behavior of an organization. Identifying path dependence engendered by organizational routines, however, also highlights tensions between, for instance, different parts of the firm learning to do different things well; it can also lead to competence traps and other biases (March, 1994), and to interferences between interdependent parts (such as departments of a firm). In consequence, organizational routines also contain (at least some) seeds of rupture. Importantly, they also provide hints for identifying such 'breaking points', for instance by analyzing the interaction effects of several organization routines (such as inefficient production routines and very efficient controlling routines).

In this issue Becker sketches a framework for thinking about the characteristics of routines and their impact on organizations. In this framework, the characteristics of recurrent interaction patterns depend on antecedents (see Becker and Knudsen, 2005, for an empirical illustration). The performance outcomes of recurrent interaction patterns are influenced by the characteristics of recurrent interaction patterns. Becker identifies a first list of dimensions for antecedents, characteristics of recurrent interaction patterns, and their performance outcomes. Other papers in this special issue further illustrate antecedents and the role they play for understanding the impact (incremental or radical) of changes on organizational routines. Reynaud, for instance, considers rules (and particular ways of rule-following) as antecedents of stabilized routines, and describes in detail the ways of rule-following in the case study.

Interdependence between the participants in a routine, and among several (nested) routines, represents a further source of endogenous change that is linked to organizational routines. Because of such interdependence, a desire by one participant in an organizational routine to substitute, say, one tool used in carrying out the routine for another, might trigger effects that result in pressure and to substitution of the old routine by a new one. As Schumpeter (1934) reminded us, innovation may have dramatic effects on prior routines and in fact might be a precondition for economic growth and for obtaining significant productivity increase. In the context of this article, it is particularly interesting to note that such a dynamic might involve both the physical and social dimensions of organizational routines. A routine, as a way of doing something in an organization, has two aspects. One is like a recipe or a program. The other is the way the work is divided up among individuals and organizational sub-units, and coordinated and managed. Description of the former naturally involves the inputs, the operations performed on them, perhaps the machinery employed to perform those operations. Description of the latter naturally involves how the work is organized. Nelson and Sampat (2001) call the former aspect of a routine the 'physical' technology involved, and the latter aspect the 'social' technology. 
While the above sources of change were endogenous, organizational routines also help to identify pathways of exogenous drivers of change. From an organizational and management perspective, the influence of managerial decisions on organizational routines is, of course, an important driver of organizational change that needs to be considered (Witt, 1998; Knott and Mc Kelvey, 1999; Knott, 2001; Foss, 2003). Many 'ways of doing things' in organizations are to a considerable extent the result of managerial decisions to carry out tasks in that particular way. Management may not have fine-grained control, but in many cases can control at least the broad outlines of what is going on. This is true of 'ways of doing things' as varied as the designs of the products being produced, and pricing policies. However, even where there is considerable high-level managerial control, there generally is a range of flexibility within which the routine can 'evolve' without management being involved. Management's influence on 'shaping' organizational routines thus seems to be limited. Within those limits, however, it consists in particular of picking templates ('best practices'), encouraging and enforcing a more or less fast and more or less precise roll-out and replication, and putting in place criteria for stopping certain practices. In addition, it provides feedback to other organization members indicating whether their efforts are, or are not, 'satisficing' with respect to managerial objectives. All of this takes place, for instance, in the process of research and development, where many physical technologies (product innovation) but also processes (process innovation) are changed periodically explicitly by decisions of management. Note that (top) management authority is often necessary (imagine the adoption of ethical criteria and its impact on bidding routines without credible commitment of top management). The example also casts light on two issues. The extent to which a routine is what it is because of high-level managerial decision, versus internal evolution, varies greatly across routines. Because of the great complexity that often characterizes actual routines in firms, problems in describing them in detail, and lack or inefficacies of instruments to influence actual processes, managerial influence is always subject to limits when it comes to influencing routines as they are actually implemented (Leibenstein, 1987; Foss, 2003; Lazaric and Raybaut, 2004). As Nelson and Winter remarked, '... routine operation is consistent with routinely occurring laxity, slippage, rule-breaking, defiance, and even sabotage' (Nelson and Winter, 1982: 108). In short, it is the actual behavior patterns that constitute the routine, not the managerially desired patterns of behavior. And it is important to remember that it is the actual processes that generate performance outcomes.

Most of the routines considered in the articles in this special issue seem to have been subject to only limited managerial control, and their state at any time was to a considerable extent determined by internal evolutionary processes. Some of them, however, were to some extent the fruits of deliberate attempts of change, such as the implementation of a global quality norm (ISO 9000) that Lazaric and Denis describe. Even in those cases, however, the papers in this special issue portray how managerial authority and the capacity to deliberately implement changes are often limited in practice. Reynaud's case study in this issue finds that employees often have important 
autonomy, impeding the managerial decisions to directly drive changes inside existing recurrent interaction patterns. Lazaric and Denis add insight in particular on the necessity of employees to have confidence in management in order to accept and carry out changes deliberately induced by management.

\section{Problems in applying routines in analyzing organizational change}

The Nelson and Winter (1982) project of fostering our understanding of organizational change by analyzing organizational routines has been slowed down somewhat by problems in applying the notion of organizational routines in empirical research. In fact, one of the most unsatisfying features of more than two decades of research on organizational routines is the slow progress in understanding how organizational routines emerge, how they change, and what impact they have on organizations. One consistent feature of articles on organizational routines is a certain dissatisfaction with such progress - and perhaps even a shadow of doubt on the possibility of making reasonable progress reasonably fast (Avery, 1996; Cohen etal., 1996; Reynaud, 1998; Jones and Craven, 2001). Taking into consideration the relatively small amount of empirical research on organizational routines, however, might shift this impression slightly to the optimistic side. As this special issue reflects, at the current stage, there is enough empirical research experience to begin sorting out the things that need sorting out, in what is indeed a complex and wide-ranging subject.

Applying the concept of routines in empirical research is not easy. Currently, researchers struggle with a number of problems (for a survey of open research questions on routines, see the international research network on organizational routines, http://www.idefi.cnrs.fr/routines). The problems center mainly on the entanglement of social and technological aspects in organizational routines, of their motivational and cognitive dimensions, and on handling several possible levels of observation.

\subsection{Social and technological aspects}

Organizational routines have both technological and social aspects, and often these are intertwined (Suchman, 1987; Weick, 1990; Vincenti, 1990; Hutchins, 1991; Weick and Roberts, 1993; Mackenzie and Spinardi, 1995). The empirical evidence, for instance, in the literature on Japanese management and production systems describes how practices such as lean manufacturing, kaizen (zero-defects) and just-in-time (JIT) manufacturing involve particular artefacts and machinery (andon cords, kanban cards, etc.), as well as particular personal attitudes (towards quality, for instance) and social practices (every employee providing suggestions, brainstorming) (Cusumano, 1985; Coriat, 1990; Womack etal., 1990; Tuckman, 1994; Kochan etal., 1997; Coriat and Dosi, 1998; Cusumano and Nobeoka, 1998; Goldstein, 1999; Victor et al., 2000; see also Winter, 1994). This literature emphasizes contrasting ways of doing things 
with the same apparent recipe (Kenney and Florida, 1990; Kilduff, 1992; Adler, 1993) and shows path dependency inside each organization. The implementation of the same global quality norms (such as ISO 9000), for example, leads to reproducing the previously existing architectures of authority in France, while in Germany, on the contrary, the autonomy of skilled workers is reinforced (see Casper and Hancké, 1999). The technological and social aspect of routines can also be related to how firms go about accomplishing tasks. Amongst the tasks organizations accomplish, technical problems and problems of organization can be distinguished. Considering that organizations solve tasks links directly to the framework presented in the article by Becker in this special issue.

The idea that organizational routines have technological and social aspects is, however, in some contrast to the way in which a good part of the literature has traditionally approached the analysis of organizational change. This asymmetry complicates applying the notion of organizational routines to understanding organizational change. Recently, the literature on the 'social nature of technology' has alleviated that contrast somewhat by casting light on the social practices of using machinery and artefacts, and on identifying how precisely the intertwining of technology and social practices of their use contributes to coordination (Suchman, 1987; Vincenti, 1990; Weick, 1990; Hutchins, 1991, 1995; Weick and Roberts, 1993; Orlikowski, 2002). Similarly, related literature has increasingly deepened our knowledge of the influence that technologies have on social practices and how they change (Barley, 1986, 1990; Orlikowski, 1996; D’Adderio, 2004).

\subsection{Motivational and cognitive dimensions}

Organizational routines also have both a motivational and a cognitive dimension. Often, the two are entangled. Nelson and Winter have reformulated this initial problem of 'quasi resolution of conflict' through the argument of the truce. In short, routine operation involves 'a comprehensive truce in intra organizational conflict' (Nelson and Winter, 1982: 110). Organization members need to be able to predict each others' behavior at least to a certain degree in order to achieve consistent coordination. While such predictability may be sustained in the face of ritualized conflict, it can hardly be so in the face of true conflict that is always taking new forms. Nelson and Winter's (1982) argument of truce is crucial for considering the motivational aspect of routines, a challenging issue on the road to understanding the endogenous evolution of firms. It has recently received renewed interest (Coriat and Dosi, 1998; Dosi et al., 2003). The entanglement of the cognitive and the motivational dimensions of organizational routines appears to be one source of confusion in operationalizing the routines concept. Descriptions of organizational routines therefore need to be sufficiently detailed in order to allow tracing the dynamics that stabilize and destabilize them, including the social dimension and the use of artefacts. That seems to be a reasonably challenging task. 
In this issue Lazaric and Denis provide an example of a description of organizational routines that identifies the motivational dimension. They explain the sluggishness of routinization processes with cognitive (such as the implementation of a new procedural and declarative memory) and motivational factors (new incentives systems, new values inside the firm, a new state of confidence towards hierarchy), and identify their consequences inside the firm: increase of stress, attention and vigilance before a new coordination is achieved. Reynaud considers difficulties in the introduction of a new wage rule. She shows that applying a different wage rule does not suffice to radically transform the division of labor and the allocation of tasks. In the allocation of tasks, for example, individual bonuses do not change the traditional way of doing things. The reason is that cooperation is crucial for interpreting the new rule and for finding an appropriate way to introduce it in a manner that is coherent with prior practices. Cooperation, however, depends crucially on motivation.

\subsection{Different levels of observation}

Routines can be observed and described on different levels, concrete and abstract. One can describe a concrete way of doing something, a recurrent action pattern at a particular place at a particular point of time, or in Winter's (1995: 149) words: 'a routine in operation at a particular site... a web of coordinating relationships connecting specific resources'. On the other hand, one can describe such a pattern at a more general level, describing its abstract form, the 'abstract activity pattern' (Winter 1995: 150; Lazaric, 2000). Feldman and Pentland (2003; this issue) elaborate this point by distinguishing what they call the ostensive and the performative aspects of routines. The ostensive part refers to 'abstract, narrative description', and the performative part consists of 'actual performances by specific people, at specific times, in specific places' (Feldman and Pentland, 2003: 95). In this special issue Feldman and Pentland argue that the abstract understandings and the specific performances (as well as artifacts) are rarely aligned precisely. Rather, they are inter-related in complex ways. For instance, the performative and ostensive aspects of routines are mutually constitutive, the ostensive guiding performances (but not determining it), but in turn being created from the performances. Because the performative aspect of routines can be best understood as inherently improvisational, it is impossible to specify routines in a complete way. As Reynaud writes in this issue, these two levels (concrete and abstract) do not only describe slightly different, if connected, things, but also 'pragmatic, local and temporary solutions to a problem to which rules provide only a theoretical, abstract and general response'.

The possibility of observing organizational routines on different levels creates several problems in empirical analysis. First, there seems to be more agreement on the appropriateness of some sort of 'dual ontology' for routines than there is on the characterization of the levels. Not surprisingly, it is the relatively abstract level of the ontology - the level that transcends the particular performances-that causes the main trouble. For example, the 'performative' level described by Feldman and Pentland 
seems quite parallel to the 'phenotypic' aspect of routines discussed by scholars who are more committed to placing the routines concept in a broader evolutionary framework (e.g. Hodgson, 2003). The relationship between the corresponding alternatives at the more abstract level-'ostensive' and 'genotypic' — is much less obvious, and probably deserves future attention. Second, regardless of specific concepts and terminology, the distinction is not an easy one to make in practice. But it does seem clear that shifting, unannounced, between the two levels of description contributes to giving a tangled description that will complicate analysis.

There are two basic kinds of problems with describing routines, problems arising from limited observability, and problems arising from the subjectivity of those who provide the limited descriptions actually available. Descriptions of routines on the performative level made by different participants in the routine can be incomplete and even contrasting (as Pentland and Feldman observe). Consider, for instance, contrasting narratives provided by those who attach normative value to the routine as 'what we are trying to do around here' and those who find such expectations oppressive or manipulative, and who may tend to doubt the sincerity of anyone that explicitly endorses such norms. Even if we admit as candidate accounts all of the accounts that participants provide, we cannot necessarily assemble a scientifically acceptable account of 'the real routine' from these.

The systematic possibility of incomplete and subjective descriptions of routines points to more fundamental concerns about the extent to which participants' descriptions might neglect some of the significant dimensions of the concept of routine that transcend the 'performative' aspect. They may miss those aspects of a routine that do not enter any narrative about it, either because they are tacit, or because the narratives employed by participants differ significantly from what more objective observers might describe, or what data from more sensitive instrumentation might inspire (aspects that are at least 'observable in principle'). An important consequence of the problems just identified is that they raise the question how to identify the instantiation of 'the same routine' in different places, either within the same organization or in different organizations. The conceptual (and observational) problem is how to capture the abstract similarity of behavioral patterns that characterizes these situationsthis pattern is the 'thing' that travels (though it is totally intangible and as such unobservable), producing new instantiations of the routine in places remote from its geographic origin, as well as in time.

\section{Advancing our knowledge of routines}

It has often been pointed out that our understanding of routines has advanced rather slowly. In the previous section we have identified and analyzed three causes of the problem that are specific to the concept of organizational routines. What, then, can scholars do to learn more about organizational routines? In this section, we propose 
two measures: to converge on a common terminology, and to use comparative research approaches to systematically contrast empirical results.

\subsection{Converging on a common terminology}

So far, researchers have often chosen different terms and definitions for describing routines, contributing to making accumulation of our knowledge on routines difficult. What authors call 'routines' often refers to slightly different things (Cohen etal., 1996). Even within the Nelson and Winter (1982) inspired literature, convergence to a widely agreed-upon conceptualization and terminology has not yet taken place (the same problem also exists between the routines literature and the literature on, say, business process reengineering, business process management, or psychology). For this reason, the results of empirical studies of what the authors call 'routines' do not accumulate easily. Have authors looked at the same construct? A lack of common terminology might be one possible explanation of apparently contradictory results (Pentland and Feldman describe another possible explanation in this issue). Becker proposes the distinction of antecedents, characteristics and performance outcomes of recurrent interaction patterns as organizing framework for comparing findings of different empirical studies.

When describing routines, it seems helpful that researchers articulate their methodology in order to indicate precisely which ontological level they refer to during their observation. The distinction between the ostensive and performative level that Pentland and Feldman introduce in their article is important in this context. It allows unpacking organizational routines and examining their internal structure. As they argue, many answers to the research questions organizational scholars have can be answered by considering the interactions between the performative and ostensive levels of organizational routines (as well as artifacts).

\subsection{Contrasting empirical results}

Several authors have pointed out the importance of experimentation for learning and the accumulation of knowledge and understanding. Winter (2000: 985) considers learning as 'occurring in a series of (on line) trials, interspersed or alternated with variable periods of off line deliberation and analysis'. Nelson (2003) argues that the ability to recognize, generate, evaluate and duplicate (on-line) variation is crucial for advancing knowledge. In terms of research on routines, one possible interpretation is that we need to learn from contrasting the results of empirical research systematically across time, space and different methods. In the long run, contrasting results further our knowledge (e.g. by presenting puzzles or pointing to weaknesses of theories), rather than weaken it. Converging empirical results from different methods will make hypotheses increasingly robust to testing, and increase the argumentative power of empirical results. While of course maintaining terminological consistency, as argued above, empirical research on identical research questions on routines and their role in 
the economy could, for instance, contrast the results generated (i) by way of different methodologies, studying the same geographical setting and point of time, (ii) with the same method in different geographical settings at the same point of time, and (iii) with the same method at the same geographical setting at different points of time.

\section{Across time}

Longitudinal studies are obviously useful for a number of research questions that involve duration, such as learning processes, evolution and development of routines, firms or other entities, and so on. Besides this well-known purpose of longitudinal studies, the additional argument for longitudinal studies provided above is that we might be able to use the systematic contrast of routines for achieving 'the same tasks' at different points of time in the same context, in order to test some hypotheses about routines. For instance, how much does the smooth functioning of a particular routine depend on slack resources, or on stress and environmental pressure? Comparing routines at the same organization at different points of time might be able to answer such questions.

The limits of proceeding in such a way are quite evident: effort and time costs for researchers are immense, and research results might accrue only slowly, depending on the periods of observation required. Moreover, the result of this kind of study is often quite difficult to replicate (or to carry out by a team of researchers) because access is usually linked to personal contacts and to trust relationships that can only be extended and transferred to others researchers to a limited extent. Practices could and should be improved here in order to enable different researchers to collect data across time and to explain such variation.

Many researchers therefore prefer to obtain information from statistics (Caroli et al,. 2001; Massini et al,. 2002; Greenan, 2003). The availability of a huge quantity of statistical information across time over a long period offers strong incentives for following this methodology. However, despite the quantity of information, the content of information on organizational practices is not usually rich enough to answer the research questions we typically have in organizational research, for instance, why some organizational practices are implemented and others are not. Much effort has to be devoted in this direction in order to combine methodologies, for instance, to start from case studies and then describe the phenomena with longitudinal statistics. Multiple methodologies can enrich each other and our knowledge about the expression of routines (the performative level), at least, could make some significant progress in combining methodologies.

\section{Across space}

Cross-site, cross-geography and cross-national research has always been seen as a method for comparative research. It is probably the most common method that systematically provides description for comparative purposes, in order to ultimately use the contrast that has thus been made visible to test hypotheses. In routine research, 
the replication of routines across different plants has been the most pursued opportunity for cross-site, cross-geography research so far (Winter, 1995; Szulansksi, 1999; Winter and Szulanski, 2001, Szulanski and Winter, 2002). The whole research literature on knowledge transfer has, moreover, applied this method in comparing the working of routines at one plant, firm or location, with those at another.

Across method

In this issue Pentland and Feldman discuss different approaches of studying organizational routines: treating routines as black boxes, examining one aspect of a routine and considering interactions between various aspects of a routine. As these different approaches, different methods also have their advantages and disadvantages, and are suited for different research questions. Utilizing various methodologies might therefore advance the endeavor of understanding organizational change by analyzing organizational routines. Simulations, lab experiments, cross-sectional field studies and longitudinal field studies do not yield the same level and kind of information on the diverse ontological levels of routines. For example, the abstract part of routines (their ostensive aspect) cannot always be discerned in simulation, lab experiments and in field studies: most of the time, the ostensive aspect is assumed as given in those methodologies, whereas longitudinal studies offer more opportunities to study this aspect. This should not, however, lead to the conclusion that only longitudinal studies capture routines because they encompass the ostensive and performative aspects of the object of study. On the contrary, in order to advance our understanding of routines and to recognize the limits of each methodology, we should seriously take these differences into account. With respect to their cognitive limitations, certain organizational models are better or worse predictors of organizational behavior. This is the reason why contrasting theoretical models with empirical data can facilitate the development of reliable information on routines. Neither should we shy away from contrasting results from the empirical study of the same phenomena (for more on multiple methodologies, see Carley, 1996), which can help to identify difference and variation. This point is also crucial for models of organizational dynamics. The more reliable knowledge we have from diverse methodologies, the more robust our findings will be.

The papers in this special section indicate other ways in which contrastive elements can be introduced that allow reading off variation and thus to learn by testing hypotheses. A first step in this direction, made in the article by Becker but building on Pentland and other work, is to make a distinction between work tasks and how they are carried out. This provides a structure for reading off variation. The more substantial suggestion developed in the special section, however, is to attempt to work in a contrastive way, comparing routines-described in the same way-across different points of time, locations, etc. Pentland and Feldman argue in this issue that one of the most interesting 'contrasts' to span, and to investigate the interactions between, is between the ostensive and performative levels of organizational routines (and artifacts). 
In summary, this article has proposed that for advancing our understanding of organizational routines, and our ability to apply it in empirical research and thereby generate interesting insight into applied research questions, we need to deal with two problems. The first is the multifariousness of the concept of organizational routines. We have identified at least three instances in which aspects of organizational routines often appear intermingled, yet can be analytically distinguished. In each case, the analysis is complicated thereby. Problems of lumping together or switching, unannounced, between ostensive and performative, social and technological, and/or motivational and cognitive aspects get further aggravated by the second problem: variation in conceptions and in terminology of organizational routines.

\section{Conclusion}

Organizational routines hold one of the keys to understanding organizational change (Nelson and Winter, 1982). They provide a unit of analysis that can capture organizational behavior at a particularly meaningful level. Because of their recurrent nature, organizational routines capture stability (and thus, what characterizes the organization). Because they encompass endogenous change, they capture important drivers of endogenous organizational change. To a certain extent, they also capture the pathways of exogenous change. In all these cases, organizational routines provide a key to identifying drivers of change and what impact these have on the organization, at a level that is at the same time concrete but not idiosyncratic (because organizational routines are recurrent).

As units of analysis, organizational routines pose some challenges, however. One of the most important is, perhaps, their multifarious nature. Possibly because they are so ubiquitous and fundamental in organizations, many different kinds of organizational routines exist. In some way or another, it is therefore necessary to distinguish different aspects of organizational routines, in order not to blend too many different issues under this label. The ostensive and performative, technological and social, and motivation and cognitive dimensions seem to be important to consider. The potential of organizational routines as units of analysis to identify and illuminate some of the instances of change can, it seems, only be unlocked if the notion of organizational routines does not lump too much together. Rather, knowing that organizational routines can be at different ends of the social-technological continuum, for instance, might help designing experiments, questionnaires, carrying out observations which can advance understanding of the research question at hand. In this issue Pentland and Feldman argue that unpacking the notion of organizational routines offers great possibilities in this regard. Rather than a 'monolithic' view of organizational routines, considering the interactions between their ostensive and performative aspects (as well as with artifacts) allows for an explanation of dynamics, such as organizational change. 
Neither developing taxonomies of different kinds of routines along these dimensions, nor exploring what particular aspects of change the different kinds of organizational routines as units of analysis might cast light on, has as yet taken place to a great extent. Doing so appears to bear much potential for advancing the application of the concept of organizational routines in empirical research. So does the twin move of increasing coherence when it comes to conceptual framework and terminology, and increasing variation for systematic comparison when it comes to empirical research. Above, we have detailed three ways in which that could be done. In all three cases, very concrete research proposals can be easily developed. In neither case has much comparative research along these lines been carried out yet. Taken together, the measures summarized briefly in this concluding section clearly indicate that much insight is still to be reaped by applying organizational routines in empirical research.

\section{References}

Adler, P. (1993), 'The learning bureaucracy: New United Motor Manufacturing, Inc.', Research in Organizational Behavior, 15, 111-194.

Avery, J. F. (1996), 'The influence of positive and negative normative feedback on the development and persistence of group routines,' Ph.D. thesis, Purdue University.

Barley, S. R. (1986), 'Technology as an occasion for structuring: evidence from the observations of CT Scanners and the social order of radiology departments,' Administrative Science Quarterly, 31, 80-108

Barley, S. P. (1990), 'The alignment of technology and structure through roles and networks,' Administrative Science Quarterly, 35, 61-103

Becker, M. C. (2004), 'Organizational routines: a review of the literature,' Industrial and Corporate Change, 13, 643-678.

Becker, M. C. and T. Knudsen, (2005), 'The role of routines in reducing pervasive uncertainty,' Journal of Business Research, 58, 746-757.

Becker M. and N. Lazaric (2003), 'The influence of knowledge in the replication of routines,' Economie Appliquée, LVI(3), 65-94.

Carley K. M. (1996), 'A comparison of artificial and human organizations,' Journal of Economic Behavior and Organization, 31, 175-191.

Caroli, E., Greenan N. and Guellec D. (2001), 'Organizational change and skill accumulation,' Industrial and Corporate Change, 10, 481-506.

Casper, S. and B. Hancké (1999), 'Global quality norms within national production regimes: ISO 9000 standards in the French and German car industries,' Organizations Studies, 20, 961-985.

Cyert, R. and J. G. March (1963), A Behavioural Theory of the Firm. Prentice-Hall: Englewood Cliffs, NJ.

Cohen, M. and P. Bacdayan (1994), 'Organizational routines are stored as procedural memory: evidence from a laboratory study,' Organization Science, 5, 554-568. 
Cohen, M. D., R. Burkhart, G. Dosi, M. Egidi, L. Marengo, M. Warglien and S. Winter (1996), 'Routines and other recurring action patterns of organizations: contemporary research issues,' Industrial and Corporate Change, 5, 653-697.

Coriat, B. and G. Dosi (1998), 'Learning how to govern and learning how to solve problems: on the co-evolution of competences, conflicts and organizational routines,' in A. Chandler, P. Hagström and O. Sövell (eds), The Dynamic Firm: The Role of Technology, Strategy, Organization and Regions, Oxford University Press: New York, pp. 103-133.

Cusamano, M. A. (1985), The Japanese Automobile Industry: Technology and Management at Nissan and Toyota. Harvard University Press: Cambridge, MA.

Cusamano, M. A. and K. Nobeoka (1998), Thinking Beyond Lean: How Multi-project Management is Transforming Product Development at Toyota and Other Companies. The Free Press: New York.

D’Adderio, L. (2004), Inside the Virtual Product_-How Organizations Create Knowledge through Software. Edward Elgar: Cheltenham.

Dosi G., D. Levinthal and L. Marengo (2003), 'Bridging contested terrain: linking incentives based and learning perspective on organizational evolution,' Industrial and Corporate Change, 12, 413-436.

Dosi, G., R. R. Nelson and S. G. Winter (2000), 'Introduction: The Nature and Dynamics of Organisational Capabilities,' in G. Dosi, R. R. Nelson, and S. G. Winter (eds), The Nature and Dynamics of Organisational Capabilities. Oxford University Press: Oxford, pp. 1-22.

Feldman, M. S. (2000), 'Organisational routines as a source of continuous change,' Organization Science, 11, 611-629.

Feldman, M. S. (2003), 'A performative perspective on stability and change in organizational routines,' Industrial and Corporate Change, 12, 727-752.

Feldman, M. S. and B. T. Pentland (2003), 'Reconceptualizing organizational routines as a source of flexibility and change,' Administrative Science Quarterly, 48, 94-118.

Foss, N. (2003), 'Selective intervention an internal hybrids: interpretating and learning from the rise and decline of the Oticon Spaghetti Organization,' Organization Science, 14, 331-349.

Goldstein, D. (1997), 'Clashing paradigms? Total quality, financial restructuring and theories of the firm,' Industrial and Corporate Change, 6, 665-700.

Greenan, N. (2003), 'Organisational change, technology, employment and skills: an empirical study of French manufacturing,' Cambridge Journal of Economics, 27, 287-316.

Hodgson, G. M. (2003), 'The mystery of the routine: the Darwinian destiny of An Evolutionary Theory of Economic Change,' Revue Economique, 54, 355-384

Hutchins, E. (1991), 'Organizing work by adaptation,' Organization Science, 2, 14-39.

Hutchins, E. (1995), 'How a cockpit remembers its speeds,' Cognitive Science, 19, 265-288

Jones, O. and M. Craven (2001), 'Beyond the routine: innovation management and the Teaching Company Scheme,' Technovation, 21, 267-279.

Kenney, M. and R. Florida (1991), 'How Japanese industry is rebuilding the Rust Belt,' Technology Review, 94(2), 24-33. 
Kilduff, M. (1992), 'Performance and interaction routines in multinational corporations,' Journal of International Business Studies, 23, 133-145.

Knott, A. M. and B. McKelvey (1999), 'Nirvana efficient: a comparative test of residual claims and routines,' Journal of Economic Behavior and Organization, 88, 365-383.

Knott, A. M. (2001), 'The dynamic value of hierarchy,' Management Science, 47, 430-448.

Kochan, T. A., R. D. Lansbury and J. P. MacDuffie (1997), After Lean Production: Evolving Employment Practices in the World Auto Industry. ILR Press: Ithaca, N.Y.

Lazaric, N. (2000), 'The role of routines, rules and habits in collective learning: some epistemological and ontological considerations,' European Journal of Economic and Social Systems, no. 2, 157-171.

Lazaric, N. and A. Raybaut (2004), 'Knowledge creation facing hierarchy: the dynamics of groups inside the firm,' Journal of Artificial Societies and Social Simulation, 7, (www:// jasss.soc.surrey.ac.uk/7/2/3/html).

Leibenstein, H. (1987), Inside the Firm: The Inefficiencies of Hierarchy. Harvard University Press: Cambridge, MA.

Mac Kenzie, D. and G. Spinardi (1995), 'Tacit knowledge, weapons design and the uninvention of nuclear weapons,' American Journal of Sociology, 101, 1.

March, J. G. (1994), A Primer on Decision-Making. The Free Press: New York.

March, J. G. and H. Simon (1958), Organizations. Wiley: New York.

Massini, S., A. Y. Lewin, T. Numagami, A. M. Pettigrew (2002), 'The evolution of organizational routines among large Western and Japanese firms,' Research Policy, 31, 1333-1348.

Nelson, R. R. (2003), 'On the uneven evolution of human know-how,' Research Policy, 32, 909-922.

Nelson, R. R. and B. N. Sampat (2001), 'Making sense of institutions as a factor shaping economic performance,' Journal of Economic Behavior and Organization, 44, 31-54.

Nelson, R. and, S. Winter (1982), An Evolutionary Theory of Economic Change. Belknap Press of Harvard University Press: Cambridge, MA.

Orlikowski, W. J. (2002), 'Knowing in practice: enacting a collective capability in distributed organizing,' Organization Science, 13, 249-273.

Orlikowski, W. J. (1996), 'Improvising organizational transformation over time: a situated change perspective,' Information Systems Research, 7, 63-92.

Pentland, B. T. and H. Rueter (1994), 'Organisational routines as grammars of action,' Administrative Sciences Quarterly, 39, 484-510.

Postrel, S. and R. Rumelt (1992), 'Incentives, routines and self command,' Industrial and Corporate Change, 1, 397-425.

Reynaud, B. (1998), 'Les propriétés des routines: outils pragmatiques de décision et modes de co-ordination collective,' Sociologie du travail, 4, 465-477.

Schumpeter, J. A. (1934), Theory of Economic Development. Harvard University Press: Cambridge, MA. 
Suchman, L. (1987), Plans and Situated Actions-The Problem of Human-Machine Communication. Cambridge University Press: Cambridge.

Szulanski, G. (1999), 'Appropriability and the challenge of scope: Banc One routinizes Replication,' in G. Dosi, R. R. Nelson, and S. G. Winter (eds), Nature and Dynamics of Organisational Capabilities. Oxford University Press: Oxford.

Szulanski, G. and S. Winter (2002), 'Getting it right the second time,' Harvard Business Review, January, 62-71.

Tuckman, A. (1994), 'The yellow brick road: total quality management and the restructuring of organizational culture,' Organization Studies, 15, 727-751.

Victor B., A. Boynton and T. Stephens-Jahng (2000), 'The effective design of work under total quality management,' Organization Science, 11, 102-117.

Vincenti, W. G. (1990), What Engineers Know and How They Know It-Analytical Studies from Aeronautical History. John Hopkins University Press: Baltimore, MD

Weick, K. E. (1990), 'The vulnerable system: an analysis of the Tenerife air disaster,' Journal of Management, 16, 571-593.

Weick, K. E. and K. H. Roberts, (1993), 'Collective mind in organizations: heedful interrelating on flight decks,' Administrative Science Quarterly, 38, 357-381.

Winter, S. G. (1994), 'Organizing for continuous improvement: evolutionary theory meets the quality revolution,' in J. Baum and J. Singh (eds), Evolutionary Dynamics of Organisations. Oxford University Press: Oxford, pp. 90-108.

Winter, S. G. (1995), 'Four Rs of profitability: rents, resources, routines, and replication,' in C. Montgomery (ed.), Resource-based and Evolutionary Theories of the Firm-Towards a Synthesis. Kluwer: Dordrecht, pp. 147-178.

Winter, S. G. (2000), 'The satisficing principle in capability learning,' Strategic Management Journal, 21, 981-996

Winter, S. G. (2003), 'Understanding dynamic capabilities,' Strategic Management Journal, 24, 991-995.

Winter, S. G. and G. Szulanski (2001), 'Replication as strategy,' Organization Science, 12, 730-743.

Witt, U. (1998), 'Imagination and leadership: the neglected dimensions of the evolutionary theory of the firm,' Journal of Economic Behaviour and Organization, 35, 161-177.

Womack, J. P., Jones D. T. and D. Roos (1991): The machine that changed the world. New York: Harper Perenniale.

Zollo, M. and S. G. Winter (2002), 'Deliberate learning and the evolution of dynamic capabilities,' Organization Science, 13, 339-351. 